\title{
Bayesian multiproxy temperature reconstruction with black spruce ring widths and stable isotopes from the northern Quebec taiga
}

\author{
Fabio Gennaretti 1 (@) David Huard ${ }^{2} \cdot$ Maud Naulier $^{3} \cdot$ Martine Savard $^{4} \cdot$ \\ Christian Bégin $^{4} \cdot$ Dominique Arseneault $^{5} \cdot$ Joel Guiot $^{1}$
}

Received: 21 July 2016 / Accepted: 31 January 2017 / Published online: 1 March 2017

(C) The Author(s) 2017. This article is published with open access at Springerlink.com

\begin{abstract}
Northeastern North America has very few millennium-long, high-resolution climate proxy records. However, very recently, a new tree-ring dataset suitable for temperature reconstructions over the last millennium was developed in the northern Quebec taiga. This dataset is composed of one $\delta^{18} \mathrm{O}$ and six ring width chronologies. Until now, these chronologies have only been used in independent temperature reconstructions (from $\delta^{18} \mathrm{O}$ or ring width) showing some differences. Here, we added to the dataset a $\delta^{13} \mathrm{C}$ chronology and developed a significantly improved millennium-long multiproxy reconstruction (997-2006 CE) accounting for uncertainties with a Bayesian approach that evaluates the likelihood of each proxy model. We also undertook a methodological sensitivity analysis to assess the different responses of each proxy to abrupt forcings such as strong volcanic eruptions.
\end{abstract}

Electronic supplementary material The online version of this article (doi:10.1007/s00382-017-3565-5) contains supplementary material, which is available to authorized users.

Fabio Gennaretti
gennaretti@cerege.fr
David Huard
huard.david@ ouranos.ca
Maud Naulier
maud.naulier@irsn.fr
Martine Savard
martinem.savard@canada.ca
Christian Bégin
christian.begin@canada.ca
Dominique Arseneault
Dominique_Arseneault@uqar.ca
Joel Guiot
guiot@cerege.fr

Ring width showed a larger response to single eruptions and a larger cumulative impact of multiple eruptions during active volcanic periods, $\delta^{18} \mathrm{O}$ showed intermediate responses, and $\delta^{13} \mathrm{C}$ was mostly insensitive to volcanic eruptions. We conclude that all reconstructions based on a single proxy can be misleading because of the possible reduced or amplified responses to specific forcing agents.

Keywords Tree-ring · Oxygen isotopes $\cdot$ Carbon isotopes · Last millennium · Summer temperature · Volcanic impact $\cdot$ Proxy sensitivity

\section{Introduction}

In North America, the network of proxy records used for high-resolution climate reconstructions over the last two millennia is dominated by tree-ring chronologies. However, these chronologies are much more abundant in the

Aix Marseille Univ, CNRS, IRD, Coll France, CEREGE, 13545 Aix-en-Provence, France

2 Ouranos Consortium, 550 Rue Sherbrooke O, H3A1B9 Montréal, Canada

3 Institut de Radioprotection et de Sûreté Nucléaire, CEA Cadarache, 13108 Saint-Paul-Lez-Durance, France

4 Geological Survey of Canada, Natural Resources Canada, 490 Rue de la Couronne, G1K9A9 Québec, Canada

5 Département de biologie, chimie et géographie, Université du Québec à Rimouski, 300 allée des Ursulines, G5L3A1 Rimouski, Canada 
west than in the east and, importantly, there are only five chronologies spanning more than a millennium north of the 50th parallel (Pages 2k Consortium 2013; http://pastglobalchanges.org/ini/wg/2k-network/intro). In northeastern North America, developing tree-ring chronologies is highly challenging due to short tree longevity, the high frequency and severity of wildfires and the remoteness of many areas (Arseneault et al. 2013). To improve the quality of reconstructions in such regions with scarce proxy data, we can both increase series replication for a single proxy by creating new chronologies, and combine proxies with an independent response to climate forcing. In this paper, we adopted the solution of combining proxies using datasets from the northern Quebec taiga. Six highly replicated millennium-long ring width chronologies were recently developed in this region by Gennaretti et al. (2014) with black spruce [Picea mariana (Mill.) B.S.P] subfossil trees preserved in six lakes. Samples from one of these sites were also used to obtain a millennium-long record of oxygen isotopic ratios $\left(\delta^{18} \mathrm{O}\right)$ in tree-ring cellulose (Naulier et al. 2015). Until now, these ring width and $\delta^{18} \mathrm{O}$ data have only been used separately in independent summer temperature reconstructions. In principle, merging these data in a multiproxy approach should provide more robust estimates of the past regional climate variations. Indeed, within a multiproxy framework, we can exploit the distinct climatic responses embedded in each proxy to reduce the impact of individual proxy errors.

Multiproxy approaches at the regional scale have already been used with successful results (Sidorova et al. 2012, 2013). For example, McCarroll et al. (2013) improved their temperature reconstruction by combining chronologies of ring width, ring density and annual tree height growth from Scandinavian sites. Boucher et al. (2011) reconstructed the full spectra of a drought index in southern South America using only the reliable periodicities specific to each of their proxies. Tolwinski-Ward et al. (2015) improved their local temperature-soil moisture reconstructions using both ring width and isotopic data within a hierarchical Bayesian approach, allowing a better understanding of the temporal changes in the climatic controls on the proxies. Such Bayesian methods are especially useful for leveraging the multi-proxy information and for assessing uncertainties with a probabilistic perspective. Bayesian models have thus been used to (1) improve climate field reconstructions from multi-proxy networks (Tingley and Huybers 2010), (2) better infer climate variability from nonlinear proxies (EmileGeay and Tingley 2016), (3) define spatially varying proxyclimate relationships (Tierney and Tingley 2014) or (4) investigate the mechanistic climate controls on the proxies (Tolwinski-Ward et al. 2013).

In this study, we present a new millennium-long $\delta^{13} \mathrm{C}$ chronology in tree-ring cellulose, which enhances the temperature-sensitive proxy dataset from the northern Quebec taiga. Thus, we use an ensemble of three proxies (ring width, $\delta^{18} \mathrm{O}$ and $\delta^{13} \mathrm{C}$ ) to provide the first multiproxy regional high-resolution summer temperature reconstruction in northeastern North America over the last millennium (997-2006 CE). A linear Bayesian approach is used to generate sharp and reliable confidence intervals based on the likelihood and the convergence of the proxy models. Finally, the sensitivity of individual proxies to temperature perturbations is evaluated and discussed, focusing the analysis on the response to strong volcanic eruptions because they produce abrupt perturbations after key-dates.

\section{Materials and methods}

\subsection{Proxy and climate data}

The tree-ring data from the northern Quebec taiga are composed of six millennium-long ring width chronologies developed with series from 1782 subfossil stem segments and 150 living black spruces (Gennaretti et al. 2014). Subfossil logs were sampled from the water and sediments of the littoral zone of six boreal lakes (the coordinates of the central point are $54.23 \mathrm{~N}$ and $71.39 \mathrm{~W}$ ), while living trees were selected in the lakeshore forest of the same sites. Their cross-sections are stored at the University of Quebec in Rimouski, and the series are already in the public domain (http://www.ncdc.noaa.gov/ paleo). Here, we used the median of the 6 millennium-long site-specific chronologies keeping for each site only periods with sample depth greater than five. Individual chronologies were built with the regional curve standardization (RCS) pivot correction method to reduce the impact of varying sampling heights (Autin et al. 2015). Low and high frequencies of the median chronology were treated separately. Low frequencies (LFs) were obtained with a 9-year triangular filter to produce a chronology comparable to that of the stable isotopes (see below). High frequencies (HFs) were obtained by subtracting the LFs from the raw chronology. The bandwidth of the LF filter at the $50 \%$ threshold was 0.07 cycles/year. The LF chronology was also transformed to obtain a quasi-perfect Gaussian distribution with the inverse transform sampling technique. This technique is based on a quantile-based transformation and, in some cases, should improve the linearity of the relationship between proxies and normally distributed climate variables (Emile-Geay and Tingley 2016; van Albada and Robinson 2007):

$y_{i}^{\prime}=\sqrt{2} e r f^{-1}\left(2 P\left(y_{i}\right)-1\right)$,

where erf represents the Gauss error function, $P(y)$ the proxy cumulative distribution function and $y_{i}$ and $y_{i}^{\prime}$ the proxy untransformed and transformed values, respectively, for year $i$. Fig. S1 (see electronic supplementary material) 
shows the effect (quite low in this case) of this transformation on the LF chronology.

From one of the six sites from the northern Quebec taiga, 60 subfossil logs and 5 living trees were further analyzed at the Delta-lab of the Geological Survey of Canada to extract two millennium-long chronologies of stable isotope ratios in tree-ring cellulose. The $\delta^{18} \mathrm{O}$ chronology is already in the public domain (Naulier et al. 2015), whereas the $\delta^{13} \mathrm{C}$ chronology is detailed here and is accessible in the supplementary material (Dataset S1). These chronologies were built with the "offset-pool plus join-point" method (Gagen et al. 2012) to obtain an annual resolution from five tree replicates (this replication was proven to be adequate to obtain robust site chronologies; Naulier et al. 2014) and successive tree cohorts. Assuming that the five time series of each cohort are realizations of the same stochastic process, this method produces chronologies equivalent to time series smoothed by the aforementioned 9-year triangular filter. Indeed, within every cohort of five trees, the rings of each tree were divided into 5-year blocks for the isotopic measurements with an offset of 1 year among trees (Naulier et al. 2015). The $\delta^{13} \mathrm{C}$ values of the modern part of the chronology were also mathematically corrected for atmospheric $\delta^{13} \mathrm{C} \mathrm{CO}_{2}$ changes due to fossil fuel combustion (Suess effect), and for plant response to increasing isotopes. The relationships between the temperature variable and the proxies over the last century are shown in Fig. S4.

\subsection{Bayesian proxy analysis}

Our objective was to infer the values of the mean July-August temperature for each year over a past period where the temperature is unknown. This inference was based on a set of known proxy values $(D)$ and temperature observations $(T)$ that overlap over a calibration period ( $\mathrm{cal}$; 1905-2006). Using Bayes' theorem, the posterior distribution of temperature $t$ at each year $i$ can be obtained by:

$p\left(t_{i} \mid D_{i}, D_{c a l}, T_{c a l}\right)=\frac{p\left(D_{i} \mid t_{i}, D_{c a l}, T_{c a l}\right) p\left(t_{i} \mid T_{c a l}, D_{c a l}\right)}{p\left(D_{i} \mid T_{c a l}, D_{c a l}\right)}$.

In Eq. (2), the first term in the numerator is the proxy likelihood, the second term of the numerator is the prior distribution for temperature, and the denominator is a normalization constant. If we assume that a model exists that estimates the proxy value given the July-August temperature and a vector of hyperparameters $(\tau)$, then the proxy likelihood can be written as:

$$
\begin{aligned}
p\left(D_{i} \mid t_{i}, D_{c a l}, T_{c a l}\right) & =\int p\left(D_{i}, \tau \mid t_{i}, D_{c a l} . T_{c a l}\right) d \tau \\
& =\int p\left(D_{i}, D_{c a l} \mid \tau, t_{i}, T_{c a l}\right) p\left(\tau \mid t_{i}, T_{c a l}\right) / p\left(D_{c a l} \mid t_{i}, T_{c a l}\right) d \tau \\
& \propto \int p\left(D_{i} \mid t_{i}, \tau\right) p\left(D_{c a l} \mid T_{c a l}, \tau\right) p(\tau) d \tau .
\end{aligned}
$$

atmospheric $\mathrm{CO}_{2}$ concentrations (McCarroll et al. 2009; McCarroll and Loader 2004; Naulier et al. 2014). The final isotope ratio chronologies are compared with the ring width LF chronology in Fig. S2. As with the ring width chronology, the isotope chronologies were also transformed with the inverse transform sampling technique (Fig. S1).

The monthly climate data for our study area (1901-2010) were downloaded from the Climatic Research Unit (CRU) TS 3.23 climate dataset (Harris et al. 2014). A correlation analysis showed that the mean of the July and August temperature was the common best fit climate signal registered by our proxies (Fig. S3). Thus, this variable was retained for the climate reconstruction. This is consistent with previous findings showing that summer temperatures control the growth and isotopic values of these trees (Gennaretti et al. 2014; Naulier et al. 2014, 2015). Low and high temperature frequencies were treated separately and obtained with the same method as for the ring width chronology such that the LF chronology was comparable with that of the stable
On the second line, the denominator term $p\left(D_{\text {cal }} \mid t_{i}, T_{\text {cal }}\right)$ appearing through the second application of Bayes theorem is again assumed constant. The third line includes, from left to right, the likelihood of the proxy datum $D_{i}$, the likelihood of the calibration data $D_{c a l}$, and the prior over-the-proxy model hyperparameters. In a sense, both the model calibration and the model prediction were merged into one formula.

The posterior can be solved by making assumptions about the likelihoods and the priors. Here, we assume that the prior over July-August temperature $t_{i}$ is a normal distribution for which parameters are given by the moments of the previous STREC reconstruction (Summer Temperature Reconstruction for Eastern Canada) based only on ring width series (Gennaretti et al. 2014):

$p\left(t_{i} \mid T_{\text {cal }}, D_{\text {cal }}\right)=p\left(t_{i}\right) \equiv N\left(t_{i} ; \mu_{\text {strec }}, \sigma_{\text {strec }}\right)$.

Next, considering that we did not find evidence of nonlinearity in the proxy-climate relationships, the model for computing the proxy likelihood can be defined by a linear regression with normally distributed errors: 
$p\left(D_{i} \mid t_{i}, \tau\right) \equiv N\left(D_{i} ; \mu=\alpha t_{i}+\beta, \sigma\right), \quad \tau \equiv(\mu, \alpha, \sigma)$.

A prior for the used hyperparameters $(\tau)$ also needs to be defined, and here, we chose non-informative priors for simplicity (Fig. S5): a uniform prior for the intercept, a Jeffreys prior for the variance and a prior for the slope that respects the invariance over the choice of dependent and independent variables (i.e., uniform prior in $\sin \left(\tan ^{-1} \alpha\right)$ ). We thus obtained the following minimally informative prior on the models:

$p(\tau) \equiv p(\alpha, \beta, \sigma) \propto \frac{\left(1+\alpha^{2}\right)^{(-3 / 2)}}{\sigma}$.

The last step is to substitute the generic data $D$ with our three proxy datasets ( $R$ for ring width, $O$ for $\delta^{18} \mathrm{O}$ and $C$ for $\delta^{13} \mathrm{C}$ ) and to introduce a set of hyperparameters specific to each proxy, denoted by $\tau_{R}, \tau_{O}, \tau_{C}$.We can now write the posterior of Eq. (2) as:
In Eq. (8), $m$ is an indexal parameter specific to each of the 7 possible combinations of proxies (R, $\mathrm{O}, \mathrm{C}, \mathrm{R} \& \mathrm{O}, \mathrm{R} \& \mathrm{C}, \mathrm{O} \& \mathrm{C}, \mathrm{R} \& \mathrm{O} \& \mathrm{C}), \quad p\left(m \mid T_{c a l}, D_{c a l}\right)$ is the posterior probability of the proxy model, $p\left(T_{\text {cal }} \mid m, D_{\text {cal }}\right)$ is the likelihood of the data given the model, and $p(m)$ is the prior probability of the model. Equation (8) is solved considering uniform model prior probabilities $(p(m)=1 / 7)$, and evaluating the likelihood of the temperature calibration data with $p\left(T_{c a l} \mid m, D_{c a l}\right)=\int p\left(T_{c a l} \mid m, D_{c a l}, \tau_{m}\right) p\left(\tau_{m}\right) d \tau_{m}$. To be clear, if $m=4$ and the proxy considered are $\mathrm{R}$ and $\mathrm{O}$, then $p\left(T_{\text {cal }} \mid m=4, D_{\text {cal }}\right)=\int p\left(T_{\text {cal }} \mid R_{\text {cal }}, \tau_{R}\right) p\left(\tau_{R}\right) d \tau_{R} p\left(T_{\text {cal }} \mid\right.$ $\left.O_{\text {cal }}, \tau_{O}\right) p\left(\tau_{O}\right) d \tau_{O}$.

\subsection{Impact of uncertainties in the proxy chronologies}

The proposed Bayesian model evaluates the capacity of the proxies to reconstruct temperature values based on

$$
\begin{aligned}
& p\left(t_{i} \mid R_{i}, R_{c a l}, O_{i}, O_{c a l}, C_{i}, C_{c a l}, T_{c a l}\right) \propto \int p\left(R_{i} \mid t_{i}, \tau_{R}\right) p\left(R_{c a l} \mid T_{c a l}, \tau_{R}\right) p\left(\tau_{R}\right) d \tau_{R} \\
& \quad \times \int p\left(O_{i} \mid t_{i}, \tau_{O}\right) p\left(O_{c a l} \mid T_{c a l}, \tau_{O}\right) p\left(\tau_{O}\right) d \tau_{O} \\
& \quad \times \int p\left(C_{i} \mid t_{i}, \tau_{C}\right) p\left(C_{c a l} \mid T_{c a l}, \tau_{C}\right) p\left(\tau_{C}\right) d \tau_{C} p\left(t_{i}\right) .
\end{aligned}
$$

In practice, Eq. (7) is solved using Markov Chain Monte Carlo (MCMC) sampling with Metropolis-Hastings steps. Instead of sampling all 10 dimensions (three hyperparameter vectors plus $t_{\mathrm{i}}$ ) at once, each hyperparameter vector is sampled independently according to $p\left(D_{\text {cal }} \mid T_{\text {cal }}, \tau\right) p(\tau)$ (Fig. S5). The samples are then used independently to obtain a temperature posterior distribution from each proxy or all together to obtain a sharper distribution using the proxy ensemble (Figs. S6, S7). The spread of the distribution of each of the proxy models is an indication of the weight (confidence) of each proxy.

To account for the fact that isotopic series were smoothed in the measurement process and their HFs were lost, the temperature LFs $\left(t^{\text {low }}\right)$ were reconstructed with the three proxies (ring width, $\delta^{18} \mathrm{O}$ and $\delta^{13} \mathrm{C}$ ), whereas the temperature HFs $\left(t^{\text {high }}\right)$ were reconstructed with ring widths only. The LF and HF components are independent, each described by a model with its set of hyperparameters (Fig. S5). The posterior distributions of $t^{\text {low }}$ and $t^{\text {high }}$ for each year $i$ were then combined in the final reconstruction.

The posterior probability of models with different combinations of LF proxies was also evaluated with the following equation (Kruschke 2014):

$p\left(m \mid T_{\text {cal }}, D_{\text {cal }}\right)=\frac{p\left(T_{c a l} \mid m, D_{\text {cal }}\right) p(m)}{\sum_{m=1}^{7} p\left(T_{c a l} \mid m, D_{c a l}\right) p(m)}$. the relationship over the calibration period and considers uncertainties in model parameter estimation. There is no source of uncertainty that depends on time in the model. However, we implicitly evaluated the impact of the time-varying uncertainties in the LF proxy chronologies, which depend on the spread of individual series. All the used proxy chronologies are built with an almost stable sample depth over the last millennium. For each year we computed the probability density of the proxy chronology values assuming that the available replicates (three to six site-specific chronologies for ring width and cohorts of five trees for isotopes) are normally distributed (Fig. S8). These probability densities were sampled 100 times to create 100 chronologies per proxy to be included in the Bayesian model. The spread of the resultant 100 temperature reconstructions represent the impact of the uncertainties in the proxy chronologies.

\section{Results and discussion}

\subsection{Final reconstruction}

The final reconstruction (Three Proxies Summer Temperature Reconstruction for Eastern Canada, hereafter 3P-STREC) and its confidence intervals were derived from the median, 5th and 95th percentiles of 

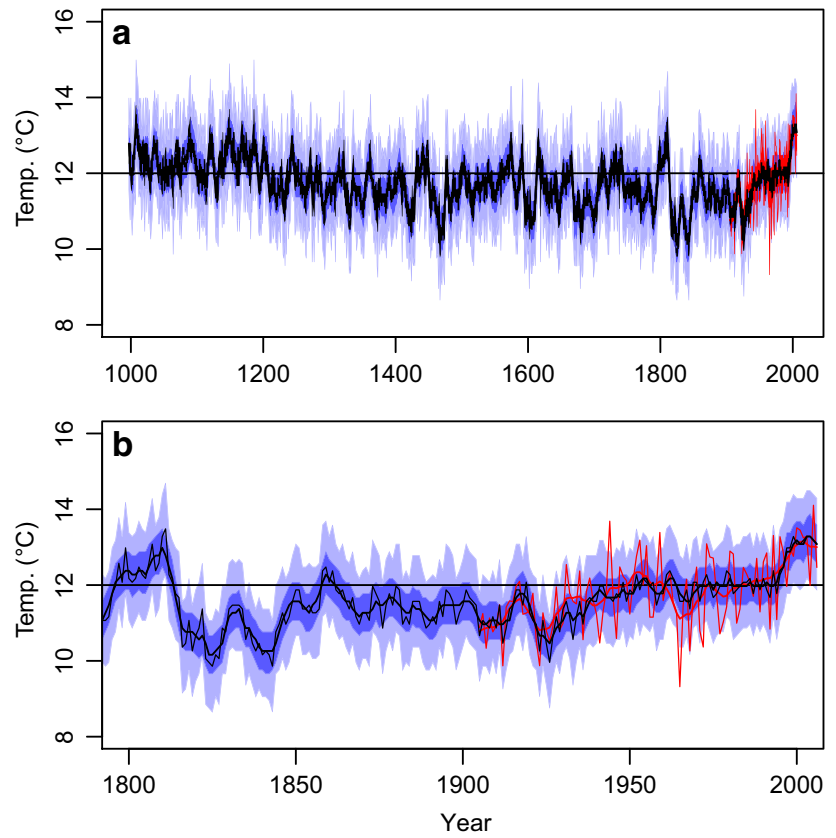

Fig. 1 The entire 3P-STREC reconstruction (a; 997-2006) and a zoom over the last two centuries (b; 1800-2006) with low frequencies only (black bold lines) and with high frequencies added (black thin lines). The $90 \%$ confidence intervals are also shown (dark blue for the low frequency reconstruction and light blue for the final reconstruction). Red lines are mean July-August temperature values (CRU TS3.23; low frequencies only with bold lines and low plus high frequencies with thin lines)

the temperature posterior densities of each year (Fig. 1). The $\mathrm{R}^{2}$ of the LF 3P-STREC versus the temperature of the last century was 0.81 . This is a substantial improvement relative to previous reconstructions with the same ring width data (STREC; $\mathrm{R}^{2}=0.64$; Gennaretti et al. 2014) or with the same $\delta^{18} \mathrm{O}$ data (i-STREC; $\mathrm{R}^{2}=0.58$ or 0.64 if considering mean maximal temperature values such as in Naulier et al. 2015). Note that here and hereafter, the comparisons with previous data were performed

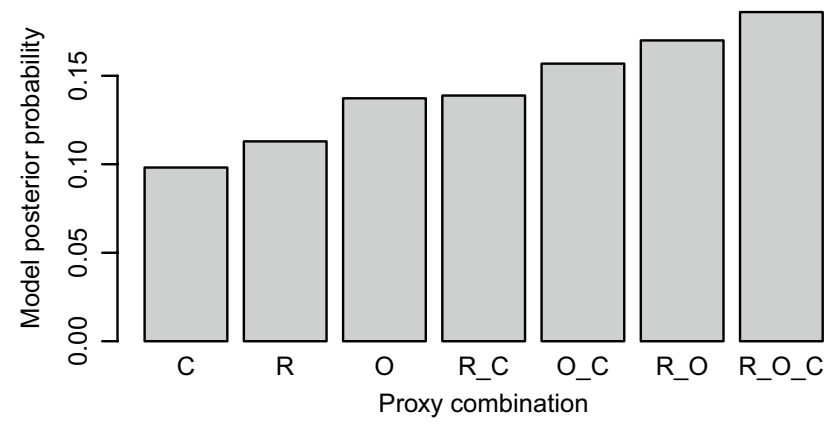

Fig. 2 Posterior probability of models with different combinations of low frequency proxies. The models are ordered according to their probability. $R$ for ring width, $O$ for $\delta^{18} \mathrm{O}$ and $C$ for $\delta^{13} \mathrm{C}$ under the same conditions (using the same climate variable, frequency components, smoothing algorithm and 1905-2006 or 997-2006 periods). The added value of the multiproxy approach is clearly shown in Fig. 2. The posterior probability of the model with the three proxies was higher than the probability obtained with any other combination of one or two proxies. The Bayesian framework also allows sharp and reliable confidence intervals to be produced by leveraging the multiproxy information. Indeed, $95.1 \%$ of the observed temperature values were inside the 90\% 3P-STREC nominal confidence intervals despite the spread of the 3P-STREC temperature posterior distributions being only $39 \%$ of the overall spread of the distributions obtained using the three proxies independently (Fig. 3a). The Bayesian model performed satisfactorily also over independent validation periods when the full period with temperature observations (1905-2006) was spit for a cross-calibration validation exercise (Table S1). The confidence intervals of 3P-STREC did not increase back in time because there is no source of uncertainty that depends on time in the model. However, the confidence intervals did not significantly vary even when we evaluated the impact of the
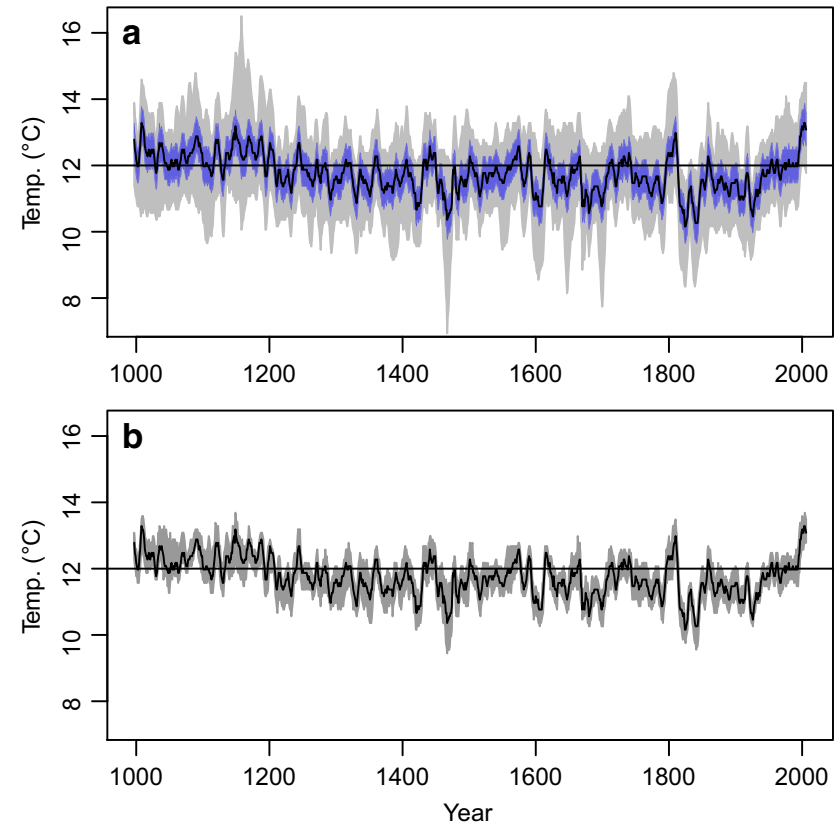

Fig. 3 Evaluation of uncertainties. a Reduction of reconstruction uncertainties with the proposed Bayesian methodology, which exploits the convergence of the three proxies. The figure shows the $90 \%$ confidence intervals of the low frequency 3P-STREC reconstruction (blue) and those derived from the sum of three independent temperature posterior densities for each year obtained from single proxies (light gray). b 90\% confidence intervals of the reconstruction when considering an independent time-varying source of uncertainty due to individual series spread in each low frequency proxy chronology (dark gray) 
time-varying uncertainties in the LF proxy chronologies (Fig. 3b). This is because the sample depths of the used chronologies were quite stable.

When the HFs (reconstructed with ring width only) were added to the LF 3P-STREC (Fig. 1), the $\mathrm{R}^{2}$ of the final reconstruction versus the temperature of the last century was 0.41 . Again, this is a notable improvement over STREC $\left(\mathrm{R}^{2}=0.30\right)$. This improvement mostly reflects the more realistic decadal and longer term signals achieved with the multiproxy approach. Indeed, HFs in 3P-STREC did not improve because they were only based on ring width data $\left(\mathrm{R}^{2}=0.11\right.$ with HF July-August temperature values; Fig. S4) and were very similar to those of STREC. A coherency plot (Fig. S9) also showed that the fidelity of 3P-STREC is especially strong at medium (frequency $=0.33$ corresponding to 3 year periodicities) and low frequencies (frequency $<0.1$ corresponding to decadal and longer time-scales). For the final 3P-STREC, $92.16 \%$ of the observed temperature values were within the $90 \%$ nominal confidence intervals. However, the inter-annual variability was underestimated because ring width HFs have a low predictive power. The development of wood density chronologies has the potential to improve the HF results.

The previous reconstructions with the same data (STREC from ring width and i-STREC from $\delta^{18} \mathrm{O}$ ) have suggested that the Medieval Climate Anomaly (MCA) was particularly warm in the Quebec taiga (Fig. 4a, b). The LF 3P-STREC confirmed this result, but it also suggested that the 15-year period between 1992 and 2006 was the warmest of the last millennium (Table S2). However, when HFs were added, some years during the Middle Ages and even during the Little Ice Age (LIA, 1300-1850) became as warm as the last decade (Fig. 1; Table S2). In addition, considering that the inter-annual variability of the final 3P-STREC was underestimated, more extreme warm years have probably occurred in the past. These findings are consistent with the fact that the MCA and the LIA were not necessarily synchronous everywhere in the World, and their intensity also varied spatially (Luterbacher et al. 2016; Mann et al. 2009). These spatial variations could be explained by regional climate feedbacks, such as those related to the Greenland sea ice and Labrador current dynamics in the case of the Quebec-Labrador peninsula (Miller et al. 2012; Schleussner and Feulner 2013; Stenchikov et al. 2009; Zanchettin et al. 2012; Zhong et al. 2011). The 3P-STREC reconstruction also allowed a better definition of the cold periods during the LIA in the Quebec taiga. According to i-STREC (Naulier et al. 2015), the coldest period in this region was between 1660 and 1700 during the Maunder solar minimum, while according to STREC (Gennaretti et al. 2014), the coldest period was between
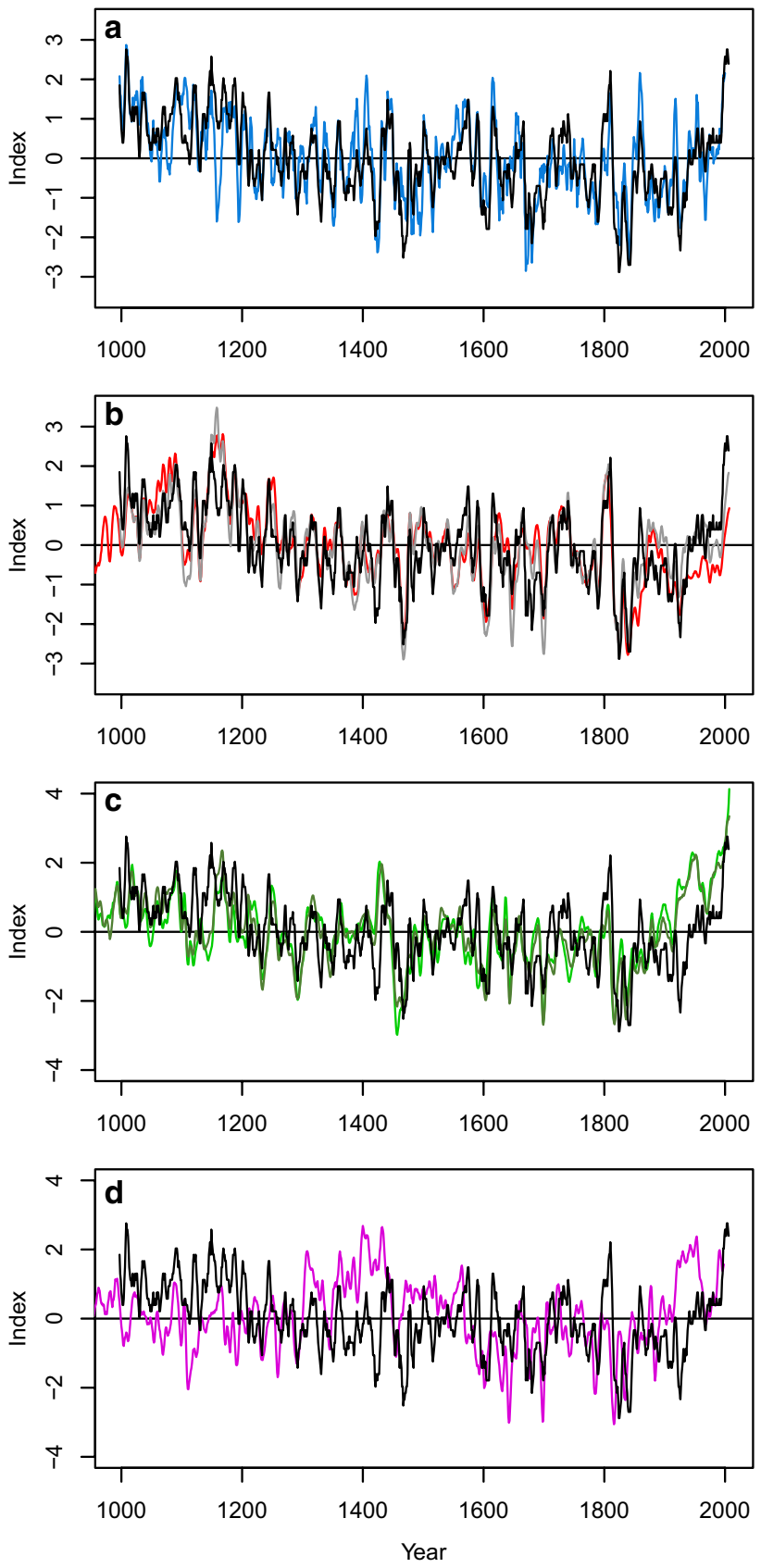

Fig. 4 Comparison with previous and other up-to-date reconstructions. a Low frequency 3P-STREC (black) compared with i-STREC (blue, Naulier et al. 2015, reconstruction using oxygen isotopes only). b Comparison with STREC (red, Gennaretti et al. 2014, reconstruction using ring width only) and a STREC variant (gray) where the chronologies are built with the pivot correction RCS method (Autin et al. 2015). c Comparison with N-TREND summer temperature reconstruction (dark green; Wilson et al. 2016) based on 54 Northern Hemisphere tree-ring records including our ring width record. The median of all records in N-TREND excluding ours is shown in light green. d Comparison with the Northern Hemisphere mid-latitude temperature reconstruction based on 15 maximum latewood density chronologies (violet; Schneider et al. 2015). All plotted series are transformed in z-scores over common periods 
1810 and 1860 coinciding with a part of the Dalton minimum and some active volcanic decades. The 3P-STREC reconstruction supported this second alternative that the first half of the nineteenth century was likely the coldest period of the LIA and of the last millennium in the Quebec taiga (Fig. 1). Another improvement achieved with the new Bayesian multiproxy reconstruction, was to confirm a more realistic long-term cooling trend over the last millennium $\left(-0.75 \pm 0.07^{\circ} \mathrm{C}\right.$ per 1000 years; estimate \pm SE; computed on the final 3P-STREC). This trend, probably due to a combination of orbital changes (Kaufman et al. 2009; Esper et al. 2012) and volcanic activity (Miller et al. 2012), is more similar to that previously reconstructed with the same $\delta^{18} \mathrm{O}$ data $\left(-0.52 \pm 0.04{ }^{\circ} \mathrm{C}\right.$ per 1000 years; i-STREC) than with the same ring width data $\left(-1.60 \pm 0.11^{\circ} \mathrm{C}\right.$ per 1000 years; STREC) and is quite consistent with values already published for nearby regions (Miller et al. 2013; Viau et al. 2012).

The concordance of 3P-STREC with the recent N-TREND Northern Hemisphere summer temperature reconstruction based on tree-ring width and density records (Wilson et al. 2016) is impressive if we exclude the last century (Fig. 4c), despite the very different spatial domain of these two reconstructions (a similar conclusion can also be drawn if the comparison is done with the reconstruction of Stoffel et al. 2015, as shown in Fig. S10). It has been suggested that few robust tree-ring chronologies along the northern North-Hemisphere treeline are sufficient to produce good estimates of reconstructions obtained with much larger networks of tree-ring data (D'arrigo and Jacoby 1993). Our study further suggests that a single regional reconstruction (maximum distance between sampling sites is $150 \mathrm{~km}$ ), extremely well replicated at the site and the tree levels (six homogeneous sites and measurements from 1932 trees), may be very similar to an hemispheric one. This concordance can be explained by the following reasons: (1) the summer temperature variations of the northern Quebec taiga are consistent with the average hemispheric variations suggesting a significant influence of large scale global forcing (solar and volcanism) on regional climate; (2) tree growth is homogeneous across the Northern Hemisphere due to some large-scale climate factor forcing an overall synchronization regardless of the species. These two hypotheses are not mutually exclusive but an argument in favor of the second one is that N-TREND is more similar to the reconstruction based on ring width only than to the other reconstructions based on $\delta^{18} \mathrm{O}$ or $\delta^{13} \mathrm{C}$ (Fig. S11). This concordance with N-TREND also highlights the importance of synchronized coolings following volcanic eruptions at both the regional and hemispheric scale (see next section). The temperature of the last century in the northern Quebec taiga appears instead anomalously low with respect to the N-TREND reconstruction. This could probably be a characteristic of our study region in response to regional climate feedback or the result of a methodological problem in the recent part of the reconstructions. Nevertheless, the situation is different when we compared 3P-STREC with another recent Northern Hemisphere summer temperature reconstruction based on only maximum latewood density chronologies (Fig. 4d; Schneider et al. 2015). Some decadal-scale fluctuations mainly due to volcanic eruptions remained similar, but important differences were visible on the century-scale fluctuations, especially before the fifteenth century and during the twentieth century. This highlights the importance of better understanding the proxy behavior (here, ring width and isotopes versus density) and producing multiproxy reconstructions to reduce possible misrepresentations.

\subsection{Proxy interpretation}

Long tree ring chronologies built from a mix of living and dead trees are often standardized using the RCS approach in order to preserve low frequency variance. However, the resulting RCS chronologies are sensitive to various sampling procedures and data treatment approaches (Melvin et al. 2013; Matskovsky and Helama 2014). In particular, Autin et al. (2015) showed that ring width chronologies combining subfossil and living trees are prone to biases if they are built with common RCS techniques. These biases are generated when the samples originate from varying heights on the trees, and they are especially strong at the recent chronology end if old living trees are all sampled at the same height in contrast with what happens with subfossils. In the previous STREC reconstruction, living trees were standardized apart from subfossil stems in order to attenuate this sampling height problem; an approach also used elsewhere to combine heterogeneous subfossil and living tree datasets (Büntgen et al. 2010, 2011). In the present study all ring width chronologies were standardized using the "pivot correction", a new variant of the RCS approach specifically designed to remove the sampling height bias in our material (Autin et al. 2015). When this method was used, the reconstruction from ring width over the last century became more similar to that from oxygen isotopes, suggesting that the previous STREC underestimated temperature during the twentieth century relative to Medieval times (Fig. 4b). Thus the ring width component included in the new 3P-STREC provides a better temperature reconstruction than the previous STREC, even if STREC is considered as a good, highly replicated dataset (Esper et al. 2016). This STREC versus 3P-STREC comparison also suggests that considering the sampling height issue elsewhere has the potential to improve RCS-based reconstructions using material with unknown or variable sampling heights. In spite of the pivot correction applied to our ring 
width series, the $\delta^{18} \mathrm{O}$ remained the most predictive LF proxy (Fig. 2, S4), generating more narrow temperature posterior densities (see Fig. S6).

Naulier et al. (2014) have previously shown that for black spruce trees of northeastern Canada, the summer mean and maximal temperatures were the most important climate parameters influencing variations of isotopic series $\left(\mathrm{r}=0.50\right.$ and 0.39 for $\delta^{13} \mathrm{C}$ and $\mathrm{r}=0.46$ and 0.54 for $\delta^{18} \mathrm{O}$, respectively). However, different climate and environmental signals can be carried by isotopic chronologies. The $\delta^{13} \mathrm{C}$ values depend on the ratio of leaf intercellular $\mathrm{CO}_{2}$ (ci) relative to the atmospheric $\mathrm{CO}_{2}$ pressure (ca), the $\delta^{13} \mathrm{C}_{\mathrm{CO} 2}$ values of ambient air (Farquhar et al. 1982), and soil moisture (Francey and Farquhar 1982). The ci/ca ratio is controlled by the photosynthetic capacity and the stomatal conductance, which itself depends on the water vapor deficit of the air (correlated with air temperature). In our case, we have already demonstrated that $\delta^{13} \mathrm{C}$ series are a good proxy for temperature reconstructions (Naulier et al. 2014). Gagen et al. (2011) have also found high correlations of their $\delta^{13} \mathrm{C}$ series with cloud cover and sunshine and with summer temperature. Young et al. (2010) showed that temperature and cloud cover may be in phase (positively correlated) or in opposition (negatively correlated), which explained the divergence between the $\delta^{13} \mathrm{C}$ series and temperature over the reconstructed 500-years period of their study. In northeastern Canada, we do not exclude the possibility that $\delta^{13} \mathrm{C}$ series could, additionally to temperature, be correlated to sunshine or cloud cover over the last millennium. However, sunshine series are not available for our study site and the short available cloud cover series (CRU) did not strongly correlate with our $\delta^{13} \mathrm{C}$ data.

The $\delta^{18} \mathrm{O}$ signal of tree-ring cellulose depends on the $\delta^{18} \mathrm{O}$ value of source water (soil). However, one of the main controls on the final $\delta^{18} \mathrm{O}$ values in tree-rings is the temperature prevailing regionally during cloud mass distillation, as registered in the raindrop signal and transferred to the source water in soils, then, through the root system, to the tree (McCarroll and Loader 2004). Additionally, $\delta^{18} \mathrm{O}$ values vary with the climatic factors influencing stomatal opening, such as temperature and moisture (McCarroll and Loader 2004; Naulier et al. 2014). For these reasons, $\delta^{18} \mathrm{O}$ series can show stronger correlation with summer temperature (in our case $r=46$ and 0.54 for mean and maximal temperature, respectively, 1945-2005 period; Naulier et al. 2014, 2015) than with hydrological parameters like precipitation amounts $(\mathrm{r}=-0.41)$ or vapor pressure deficit $(\mathrm{r}=0.44)$. The $\delta^{18} \mathrm{O}$ chronology used in this study was previously demonstrated to be a good proxy for temperature reconstruction (Naulier et al. 2014, 2015), a coherent finding owing to the fact that the studied area has a boreal climate not subjected to drought periods and that the collected trees were riparian and consequently, never under water stress.

In the end, it appears that ring widths, $\delta^{13} \mathrm{C}$ and $\delta^{18} \mathrm{O}$ chronologies have strengths and weaknesses as proxy of past temperature. However, they can generate complementary information, and when we used the three proxies together, the performance of the proposed Bayesian model increased (Fig. 2).

\subsection{Proxy sensitivity to volcanic eruptions}

The Bayesian framework can also be used to analyze the proxy differential sensitivity to climate forcings. Here we focused on the impact of volcanic eruptions because they produce abrupt temperature perturbations after known dates. Conversely, the impacts of the other forcings (solar and anthropogenic), although they are significant, are much more smoothed and difficult to isolate from other influences. In general, volcanic perturbations on temperature should be short lasting: 1-3 years for some authors (Fischer et al. 2007; Stoffel et al. 2015) or up to 10 years for others (Sigl et al. 2015). However, some uncertainties on these durations remain because the last century, having a robust observation network, is a period with relatively weak volcanism. Furthermore, some data and climate model experiments suggest that the impact of strong volcanic eruptions on temperature is much longer lasting if sustained by sea ice/ocean feedback, especially when two or more strong eruptions occur in close succession (Miller et al. 2012; Schleussner and Feulner 2013; Stenchikov et al. 2009; Zanchettin et al. 2012; Zhong et al. 2011). It was also hypothesized that a series of strong volcanic eruptions during the twelfth and thirteenth centuries triggered the onset of the LIA in the eastern Canadian Arctic and in northeastern North America (Miller et al. 2012). These suggestions appear to be supported by the volcano-induced regime shifts that we found in our ring width chronologies (Gennaretti et al. 2014). However, using tree-ring proxy data and especially ring width, it is hard to discriminate the volcanic impact on temperature (i.e., the object of the reconstruction) from other collateral volcanic impacts, including tree damage, reductions in solar irradiance and changes in diffuse radiation (Robock 2005). In particular, it is considered that ring width series show a smeared delayed response to volcanic eruptions in comparison with instrumental temperature values and tree-ring density data due to their greater autocorrelation (Esper et al. 2013, 2015). Consequently, ring width series are considered inappropriate to examine the response to volcanism at interannual scale (D'Arrigo et al. 2013). Similarly, our smoothed isotopic data do not seem to be appropriate. However, as STREC and 3P-STREC contain a low-frequency signal linked to volcanism in response to very strong eruptions 
Table 1 List of 46 eruption years derived from Gao et al. (2008; global total stratospheric sulfate aerosol injection $>15 \mathrm{Tg}$ ), Crowley and Unterman (2013; satellite aerosol optical depth >0.1), Esper et al. (2013; eruptions classified as large events) or Sigl et al. (2013, 2015; eruptions classified as large events)

\begin{tabular}{|c|c|c|c|}
\hline Date & Volcano & Location & Derived from \\
\hline 1108 & Unknown & Unknown & Sigl \\
\hline 1167 & Unknown & Unknown & Gao \\
\hline 1171 & Unknown & Unknown & Sigl \\
\hline 1176 & Unknown & Unknown & Gao \\
\hline 1188 & Unknown & Unknown & Gao; Sigl \\
\hline 1227 & Unknown & Unknown & Gao; Crowley \\
\hline 1230 & Unknown & Unknown & Sigl \\
\hline 1258 & Samalas & Indonesia & Gao; Sigl; Crowley \\
\hline 1262 & Katla & Iceland & Esper \\
\hline 1284 & Unknown & Unknown & Gao \\
\hline 1286 & Quilotoa? & Ecuador & Sigl; Crowley \\
\hline 1345 & El Chichon? & Mexico & Sigl \\
\hline 1362 & Oraefajokull & Iceland & Esper \\
\hline 1452 & Unknown & Unknown & Gao; Sigl \\
\hline 1458 & Kuwae & Vanuatu & Sigl; Crowley \\
\hline 1459 & Kuwae & Vanuatu & Gao \\
\hline 1477 & Barbarbunga & Iceland & Esper \\
\hline 1584 & Colima & Mexico & Gao \\
\hline 1594 & Ruiz & Columbia & Sigl \\
\hline 1600 & Huaynaputina & Peru & Gao; Esper; Crowley \\
\hline 1601 & Huaynaputina & Peru & Sigl \\
\hline 1625 & Katla & Iceland & Esper \\
\hline 1630 & Furnas & Azores & Esper \\
\hline 1640 & Komaga-Take & Japan & Esper \\
\hline 1641 & Parker Peak & Philippines & Gao; Sigl; Crowley \\
\hline 1663 & Usu & Japan & Esper \\
\hline 1667 & Shikotsu & Japan & Esper \\
\hline 1695 & Unknown & Unknown & Sigl; Crowley \\
\hline 1707 & Fuji & Japan & Esper \\
\hline 1719 & Unknown & Unknown & Gao \\
\hline 1739 & Shikotsu & Japan & Esper \\
\hline 1755 & Katla & Iceland & Esper \\
\hline 1783 & Laki & Iceland & Gao; Sigl \\
\hline 1809 & Unknown & Unknown & Gao; Sigl; Crowley \\
\hline 1815 & Tambora & Indonesia & Gao; Sigl; Esper; Crowley \\
\hline 1831 & Babuyan & Philippines & Gao; Sigl \\
\hline 1835 & Cosiguina & Nicaragua & Gao; Sigl; Esper; Crowley \\
\hline 1854 & Shiveluch & Russia & Esper \\
\hline 1875 & Askja & Iceland & Esper \\
\hline 1883 & Krakatau & Indonesia & Esper; Crowley \\
\hline 1902 & Santa Maria & Guatamala & Esper \\
\hline 1907 & Ksudach & Russia & Esper \\
\hline 1912 & Katmai & USA & Esper \\
\hline 1913 & Colima & Mexico & Esper \\
\hline 1956 & Bezymianny & Russia & Esper \\
\hline 1991 & Pinatubo & Indonesia & Sigl; Crowley \\
\hline
\end{tabular}

(an influence that extends up to 20 years in some cases), it is interesting to compare the volcanic signal between the ring width and isotopic components of 3P-STREC, even if this comparison would be based on smoothed data (chronologies equivalent to series smoothed with a 9-year triangular filter).

To verify whether the isotope ratios show the same sensitivity to volcanic eruptions as the ring width, we first compared the responses from their independent LF reconstructions (i.e., based on a single proxy) to each of the 46 strong volcanic eruptions listed in Table 1 (Fig. 5). These eruptions were derived from Gao et al. (2008), Crowley and Unterman (2013), Esper et al. (2013) or Sigl et al. $(2013,2015)$. In the figure, the y-axis shows the subtraction between the post-eruption anomalies reconstructed from isotope ratios (average anomalies from $\delta^{18} \mathrm{O}$ and $\delta^{13} \mathrm{C}$ ) and from ring width. Positive (negative) values indicate that post-eruption anomalies are more negative in the reconstruction from ring width (isotope ratios). We can thus see that ring width indexes often reconstruct more negative temperature anomalies after volcanic events (Fig. 5b) than isotopic proxies, confirming the different proxy sensitivity to volcanic forcing. However, the variability of responses after different eruptions is large. Indeed different volcano locations, atmospheric states during the eruptions, event intensities and days of the year may cause specific impacts over the Quebec-Labrador peninsula, which are more or less registered by the proxies.

Subsequently, we focused on the three periods of the last millennium where the volcanic impact should have been the strongest and for which Gennaretti et al. (2014) found significant regime shifts toward lower growth values in the ring width chronologies. These periods are the thirteenth century with the series of eruptions centered around the 1258 Samalas event and that supposedly triggered the onset of the LIA; the second half of the fifteenth century with the cooling episode following the 1458-1459 Kuwae eruption; and the first half of the nineteenth century, probably the coldest period of the last millennium in the Quebec taiga, with a series of eruptions centered around the 1815 Tambora event. This analysis (Fig. 6) reveals that $\delta^{13} \mathrm{C}$ of spruce trees growing on lakeshores is almost insensitive to volcanic impacts. It is also clear that ring width shows much more important volcanic impacts than $\delta^{18} \mathrm{O}$, reconstructing the strongest coolings after single events and the strongest cumulative impacts from multiple events. Interestingly, during the thirteenth century at the onset of the LIA, all three proxies agree in reconstructing an overall cooling trend despite the amplitude of the trend and short-term temperature variations depending on the proxies. In this case, the impact of individual eruptions appears not correlated to their intensity. Indeed, following the 1258 Samalas eruption, which was likely the strongest of the last millennium 

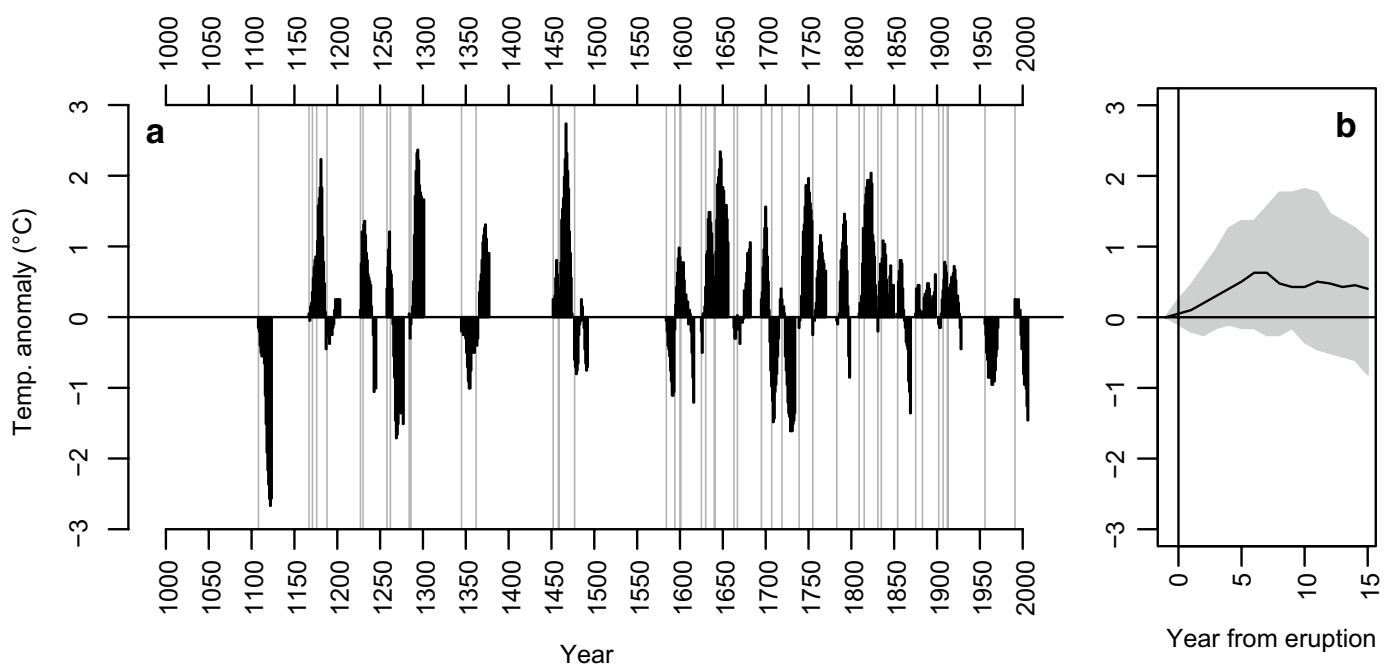

Fig. 5 Comparison of responses from low frequency reconstructions based on ring width and isotopic proxies to individual strong volcanic eruptions of the last millennium (listed in Table 1). Plot a shows if the anomalies of each 15 post-eruption years (anomalies relative to the year before the eruption) are more negative in the reconstruc-

(Lavigne et al. 2013), the proxies react as after other strong eruptions of the same period. During the second half of the fifteenth century, $\delta^{18} \mathrm{O}$ and ring width strongly disagree in the volcanic responses. While $\delta^{18} \mathrm{O}$ shows only moderate coolings (approximately $-0.5^{\circ} \mathrm{C}$ ) lasting for no more than 3 years after the two strong eruptions of 1452 and 1458-1459, ring width displays an important cumulative impact of these two events, culminating in anomalies of approximately $-3.5^{\circ} \mathrm{C}$ (note that this discussion on cooling intensities and durations is based on smoothed data because only low frequencies are available for isotope ratios due to the data processing method). A good proxy agreement is instead observed during the first half of the nineteenth century where the decadal trends in $\delta^{18} \mathrm{O}$ and ring width are very similar despite ring width again showing larger temperature variations. The LF 3P-STREC reconstruction with the ensemble of the proxies always has an intermediate behavior between the $\delta^{18} \mathrm{O}$ and the ring width reconstructions with a preference towards $\delta 180$ which is likely the better estimate of past temperatures.

As this comparison of the proxy differential sensitivity to volcanic eruptions showed that ring width LFs responded more strongly than isotopic ones, it is possible that the ring width component of 3P-STREC amplifies the volcanic forcing after strong eruptions (see Büntgen et al. 2015). This may be the case especially in cold periods, such as the Little Ice Age, and/or if the time between successive eruptions is short (Sigl et al. 2013). Indeed, in cold periods with recurrent volcano-induced temperature reductions, tree growth is likely to suffer from the depletion of carbohydrate reserves and from the fact that the tissues and tion from ring width (positive values) or from stable isotope ratios (negative values; average anomalies from $\delta^{18} \mathrm{O}$ and $\delta^{13} \mathrm{C}$ ). Eruption years are vertical lines. Plot $\mathbf{b}$ shows a Superimposed Epoch Analysis (median and 60\% confidence intervals) based on the data and the eruption years of plot $\mathbf{a}$

canopy can be frost-damaged. Conversely, it is also possible that the isotopic proxies are less sensitive to the meteorological perturbations related to volcanic events. Latewood maximum density data, which nevertheless could also have their limitations (see Stine and Huybers 2014; Tingley et al. 2014), may be useful to discriminate between these hypotheses.

\section{Conclusion}

In this paper, we presented the first annually resolved and millennium-long multiproxy temperature reconstruction for northeastern North America based on tree-ring width and stable isotope ratios $\left(\delta^{13} \mathrm{C}\right.$ and $\left.\delta^{18} \mathrm{O}\right)$. The climate information embedded in the three proxies was exploited using a Bayesian framework that allows for a rigorous uncertainty assessment. The results showed that the final reconstruction 3P-STREC was a clear improvement over previous attempts based only on ring width or $\delta^{18} \mathrm{O}$ values. Using the Bayesian methodology, we can also provide reliable confidence intervals that are much sharper than simply merging the three independent reconstructions from single proxies. At the moment, 3P-STREC represents the best estimate of the past summer temperature of our region (the mean of July-August temperature), but in the future, the results could be further improved by (1) adding additional proxies (e.g., ring maximum density) to reduce the remaining sources of LF errors and improve the HF calibration, (2) considering more complex mechanistic modeling of the proxy-climate relationships, (3) providing a more robust 
(a) Volcanic impact during the $13^{\text {th }}$ century

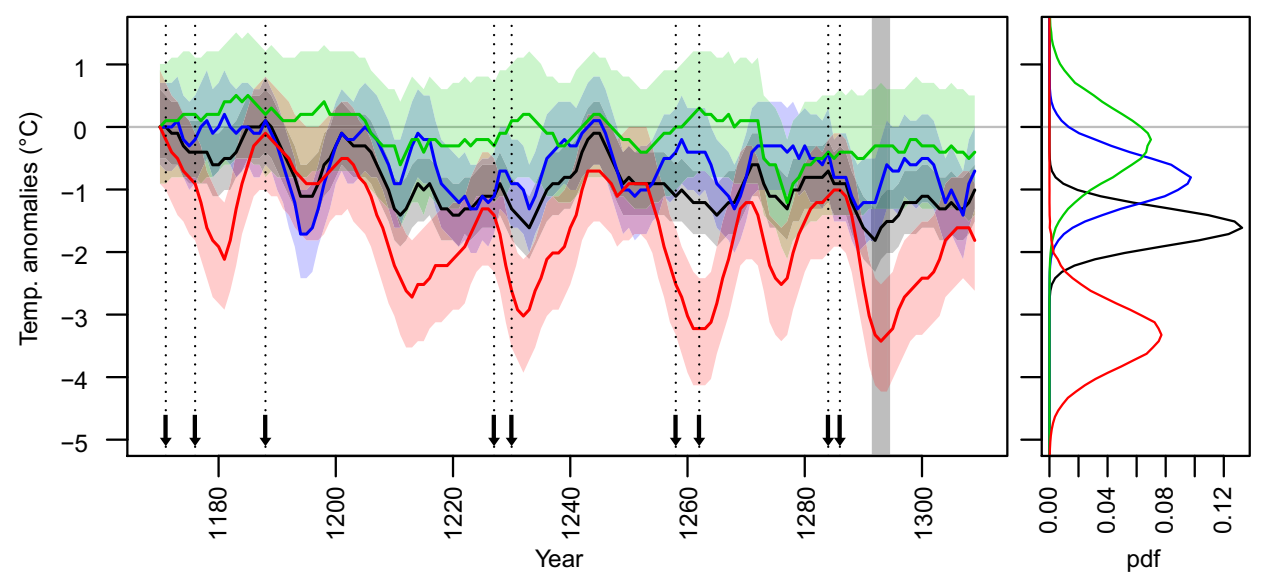

(b) Volcanic impact during the second half of the $15^{\text {th }}$ century

(c) Volcanic impact during the first half of the $19^{\text {th }}$ century
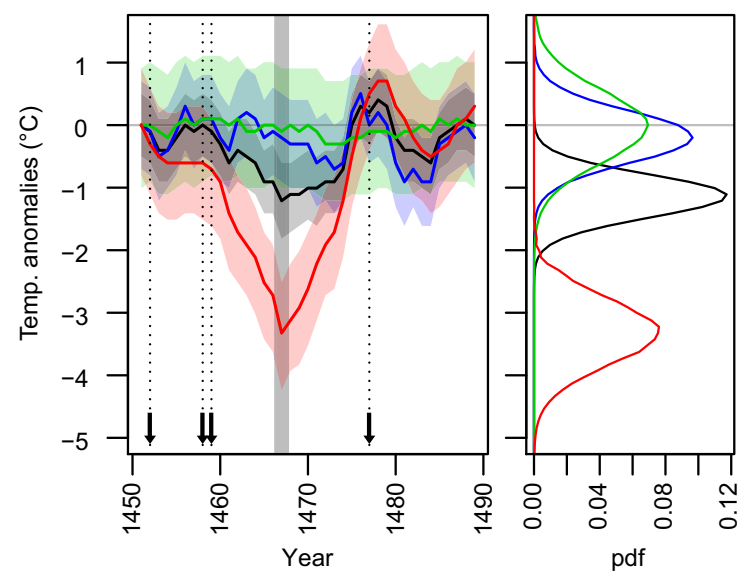

Fig. 6 Proxy response during periods of strong volcanic impact: the thirteenth century (a), the second half of the fifteenth century (b) and the first half of the nineteenth century (c). Temperature anomalies with respect to the first considered year are shown on the left of each panel (medians and 90\% confidence intervals), and anomaly posterior densities of the year with lowest anomalies are shown on the right

intra- and inter-site-explicit uncertainty analysis, or (4) taking into account the year to year memory of each component in the model as a fractional Gaussian process (Lovejoy et al. 2015) in order to properly integrate the information from different sources ( $\mathrm{Li}$ et al. 2010) and investigate the impact of higher long-term persistence in ring width data compared to instrumental data (Zhang et al. 2015). However, concerning this last point, we want to stress out that 3P-STREC is already shown to be well calibrated in the LF domain.

We also examined different proxy sensitivities to climate forcing, focusing the analysis on the impact of volcanic eruptions. The reconstruction from ring width had a larger and longer response to single or consecutive eruptions, while those from isotope ratios showed an intermediate $\left(\delta^{18} \mathrm{O}\right)$ or nearly absent $\left(\delta^{13} \mathrm{C}\right)$ volcanic impact. It is

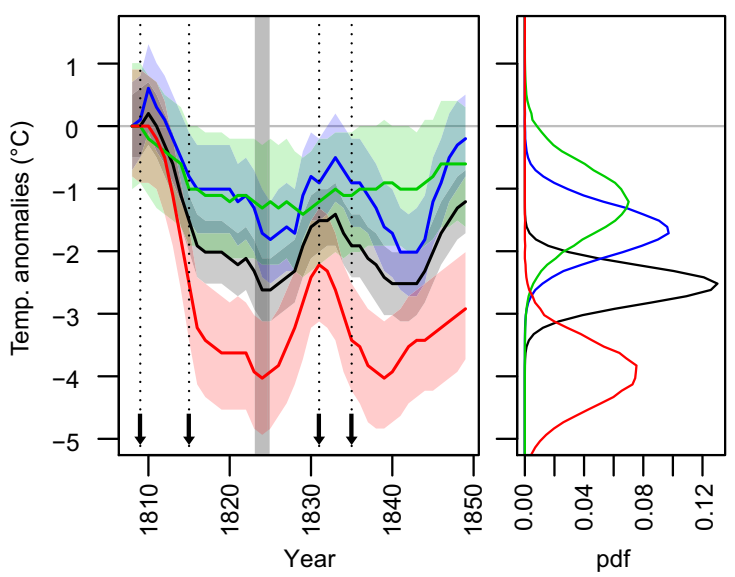

(the selected year is highlighted by a vertical gray bar on the left plots). Black colors for the proxy ensemble low frequency reconstruction 3P-STREC, red for the reconstruction using ring width only, blue for $\delta^{18} \mathrm{O}$ and green for $\delta^{13} \mathrm{C}$. Vertical dotted lines and arrows indicate eruption years listed in Table 1

difficult to know the real influence of past volcanic events on temperature at the regional scale because many uncertainties exist due to (1) the limited knowledge on the mechanisms behind the proxy responses, (2) the absence of major volcanic events during the period when the proxies are compared with instrumental data, (3) the low agreement in the volcanic datasets concerning timing and respective forcing of eruptions (Crowley and Unterman 2013; Esper et al. 2013; Gao et al. 2008; Sigl et al. 2013, 2015), and (4) the complexity of comparing the results of proxy-based reconstructions with simulations of past climate with plausible initial conditions, sulfate aerosols and ocean feedback (circulation, sea ice, relaxation time of subsurface temperature and sea level) during volcanic coolings (Stenchikov et al. 2009). In our reconstruction, the uncertainties came from the specific reduced 
or amplified responses to volcanic eruptions of the three temperature-sensitive proxies. We should bear in mind that each proxy has its advantages and drawbacks. Only a multi-proxy approach can allow us to take advantage of the proxy convergence and reduce individual sources of error caused by specific mechanistic responses of the proxies.

Acknowledgements This project has received funding from the European Union's Horizon 2020 research and innovation programme under the Marie Sklodowska-Curie grant agreement No 656896. The $\delta^{13} \mathrm{C}$ series has been produced through the support of the Environmental Geoscience program of the Geological Survey of Canada.

Open Access This article is distributed under the terms of the Creative Commons Attribution 4.0 International License (http:// creativecommons.org/licenses/by/4.0/), which permits unrestricted use, distribution, and reproduction in any medium, provided you give appropriate credit to the original author(s) and the source, provide a link to the Creative Commons license, and indicate if changes were made.

\section{References}

Arseneault D, Dy B, Gennaretti F, Autin J, Bégin Y (2013) Developing millennial tree ring chronologies in the fire-prone North American boreal forest. J Quat Sci 28:283-292. doi:10.1002/ jqs. 2612

Autin J, Gennaretti F, Arseneault D, Bégin Y (2015) Biases in RCS tree ring chronologies due to sampling heights of trees. Dendrochronologia 36:13-22. doi:10.1016/j.dendro.2015.08.002

Boucher E, Guiot J, Chapron E (2011) A millennial multi-proxy reconstruction of summer PDSI for Southern South America. Clim Past 7:957-974. doi:10.5194/cp-7-957-2011

Büntgen U, Trouet V, Frank D, Leuschner HH, Friedrichs D, Luterbacher J, Esper J (2010) Tree-ring indicators of German summer drought over the last millennium. Quat Sci Rev 29:1005-1016. doi:10.1016/j.quascirev.2010.01.003

Büntgen U et al (2011) 2500 years of European climate variability and human susceptibility. Science 331:578-582. doi:10.1126/ science. 1197175

Büntgen U et al (2015) Tree-ring amplification of the early nineteenth-century summer cooling in Central Europe. J Clim 28:5272-5288. doi:10.1175/jcli-d-14-00673.1

Crowley TJ, Unterman MB (2013) Technical details concerning development of a 1200 year proxy index for global volcanism. Earth Syst Sci Data 5:187-197. doi:10.5194/essd-5-187-2013

D'arrigo RD, Jacoby GC (1993) Secular trends in high northern latitude temperature reconstructions based on tree rings. Clim Change 25:163-177. doi:10.1007/BF01661204

D'Arrigo R, Wilson R, Anchukaitis KJ (2013) Volcanic cooling signal in tree ring temperature records for the past millennium. J Geophys Res D Atmos 118:9000-9010. doi:10.1002/jgrd.50692

Emile-Geay J, Tingley M (2016) Inferring climate variability from nonlinear proxies: application to palaeo-ENSO studies. Clim Past 12:31-50. doi:10.5194/cp-12-31-2016

Esper J et al (2012) Orbital forcing of tree-ring data. Nat Clim Change 2:862-866. doi:10.1038/nclimate1589

Esper J et al. (2013) European summer temperature response to annually dated volcanic eruptions over the past nine centuries. Bull Volcanol 75:1-14. doi:10.1007/s00445-013-0736-z
Esper J, Schneider L, Smerdon JE, Schöne BR, Büntgen U (2015) Signals and memory in tree-ring width and density data. Dendrochronologia 35:62-70. doi:10.1016/j.dendro.2015.07.001

Esper J et al. (2016) Ranking of tree-ring based temperature reconstructions of the past millennium. Quat Sci Rev 145:134-151. doi:10.1016/j.quascirev.2016.05.009

Farquhar GD, O'Leary MH, Berry JA (1982) On the relationship between carbon isotope discrimination and the intercellular carbon dioxide concentration in leaves. Aust J Plant Physiol 9:121137. doi:10.1071/PP9820121

Fischer EM, Luterbacher J, Zorita E, Tett SFB, Casty C, Wanner H (2007) European climate response to tropical volcanic eruptions over the last half millennium. Geophys Res Lett 34:L05707. doi: 10.1029/2006g1027992

Francey RJ, Farquhar GD (1982) An explanation of 13 C/12 C variations in tree rings. Nature 297:28-31. doi:10.1038/297028a0

Gagen $M$ et al (2011) Cloud response to summer temperatures in Fennoscandia over the last thousand years. Geophys Res Lett 38:L05701. doi:10.1029/2010g1046216

Gagen M, McCarroll D, Jalkanen R, Loader NJ, Robertson I, Young GHF (2012) A rapid method for the production of robust millennial length stable isotope tree ring series for climate reconstruction. Global Planet Change 82-83:96-103. doi:10.1016/j. gloplacha.2011.11.006

Gao C, Robock A, Ammann C (2008) Volcanic forcing of climate over the past 1500 years: an improved ice core-based index for climate models. J Geophys Res Atmos 113:D23111. doi:10.10 29/2008jd010239

Gennaretti F, Arseneault D, Nicault A, Perreault L, Bégin Y (2014) Volcano-induced regime shifts in millennial tree-ring chronologies from northeastern North America. Proc Natl Acad Sci USA 111:10077-10082. doi:10.1073/pnas.1324220111

Harris I, Jones PD, Osborn TJ, Lister DH (2014) Updated highresolution grids of monthly climatic observations-the CRU TS3.10 Dataset. Int J Climatol 34:623-642. doi:10.1002/ joc. 3711

Kaufman DS et al (2009) Recent warming reverses long-term arctic cooling. Science 325:1236-1239. doi:10.1126/science.1173983

Kruschke JK (2014) Doing Bayesian data analysis: a tutorial with R, JAGS, and Stan, 2nd edn. Elsevier Science, Amsterdam. doi:10.1016/b978-0-12-405888-0.09999-2

Lavigne F et al (2013) Source of the great A.D. 1257 mystery eruption unveiled, Samalas volcano, Rinjani Volcanic Complex, Indonesia. Proc Natl Acad Sci USA 110:16742-16747. doi:10.1073/ pnas. 1307520110

Li B, Nychka DW, Ammann CM (2010) The value of multiproxy reconstruction of past climate. J Am Stat Assoc 105:883-895. doi:10.1198/jasa.2010.ap09379

Lovejoy S, Del Rio Amador L, Hébert R (2015) The ScaLIng Macroweather Model (SLIMM): using scaling to forecast globalscale macroweather from months to decades. Earth Syst Dyn 6:637-658. doi:10.5194/esd-6-637-2015

Luterbacher $\mathrm{J}$ et al. (2016) European summer temperatures since Roman times. Environ Res Lett 11:024001. doi:10.1088/1748-9326/11/2/024001

Mann ME et al (2009) Global signatures and dynamical origins of the little ice age and medieval climate anomaly. Science 326:12561260. doi:10.1126/science. 1177303

Matskovsky VV, Helama S (2014) Testing long-term summer temperature reconstruction based on maximum density chronologies obtained by reanalysis of tree-ring data sets from northernmost Sweden and Finland. Clim Past 10:1473-1487. doi:10.5194/ cp-10-1473-2014

McCarroll D, Loader NJ (2004) Stable isotopes in tree rings. Quat Sci Rev 23:771-801. doi:10.1016/j.quascirev.2003.06.017 
McCarroll D et al. (2009) Correction of tree ring stable carbon isotope chronologies for changes in the carbon dioxide content of the atmosphere. Geochim Cosmochim Acta 73:1539-1547. doi:10.1016/j.gca.2008.11.041

McCarroll D et al (2013) A 1200-year multiproxy record of tree growth and summer temperature at the northern pine forest limit of Europe. Holocene 23:471-484. doi: $10.1177 / 0959683612467483$

Melvin TM, Grudd H, Briffa KR (2013) Potential bias in 'updating' tree-ring chronologies using regional curve standardisation: reprocessing 1500 years of Torneträsk density and ring-width data. Holocene 23:364-373. doi:10.1177/0959683612460791

Miller GH et al (2012) Abrupt onset of the Little Ice Age triggered by volcanism and sustained by sea-ice/ocean feedbacks. Geophys Res Lett 39:L02708. doi:10.1029/2011g1050168

Miller GH, Lehman SJ, Refsnider KA, Southon JR, Zhong Y (2013) Unprecedented recent summer warmth in Arctic Canada. Geophys Res Lett 40:5745-5751. doi:10.1002/2013g1057188

Naulier M, Savard MM, Bégin C, Marion J, Arseneault D, Bégin Y (2014) Carbon and oxygen isotopes of lakeshore black spruce trees in northeastern Canada as proxies for climatic reconstruction. Chem Geol 374-375:37-43. doi:10.1016/j. chemgeo.2014.02.031

Naulier M et al. (2015) A millennial summer temperature reconstruction for northeastern Canada using oxygen isotopes in subfossil trees. Clim Past 11:1153-1164. doi:10.5194/cp-11-1153-2015

Pages 2k Consortium (2013) Continental-scale temperature variability during the past two millennia. Nat Geosci 6:339-346. doi:10.1038/ngeo1797

Robock A (2005) Cooling following large volcanic eruptions corrected for the effect of diffuse radiation on tree rings. Geophys Res Lett 32:1-4. doi:10.1029/2004g1022116

Schleussner CF, Feulner G (2013) A volcanically triggered regime shift in the subpolar North Atlantic Ocean as a possible origin of the Little Ice Age. Clim Past 9:1321-1330. doi:10.5194/ cp-9-1321-2013

Schneider L, Smerdon JE, Büntgen U, Wilson RJS, Myglan VS, Kirdyanov AV, Esper J (2015) Revising midlatitude summer temperatures back to A.D. 600 based on a wood density network. Geophys Res Lett 42:GL063956. doi:10.1002/2015gl063956

Sidorova OV et al. (2012) A multi-proxy approach for revealing recent climatic changes in the Russian Altai. Clim Dyn 38:175188. doi:10.1007/s00382-010-0989-6

Sidorova OV et al (2013) The application of tree-rings and stable isotopes for reconstructions of climate conditions in the Russian Altai. Clim Change 120:153-167. doi:10.1007/ s10584-013-0805-5

Sigl M et al (2013) A new bipolar ice core record of volcanism from WAIS divide and NEEM and implications for climate forcing of the last 2000 years. J Geophys Res Atmos 118:1151-1169. doi:1 $0.1029 / 2012 \mathrm{jd} 018603$

Sigl $\mathrm{M}$ et al (2015) Timing and climate forcing of volcanic eruptions for the past 2,500 years. Nature 523:543-549. doi:10.1038/ nature 14565
Stenchikov G, Delworth TL, Ramaswamy V, Stouffer RJ, Wittenberg A, Zeng F (2009) Volcanic signals in oceans. J Geophys Res Atmos 114:D16104. doi:10.1029/2008jd011673

Stine AR, Huybers P (2014) Arctic tree rings as recorders of variations in light availability. Nat Commun 5:1-8. doi:10.1038/ ncomms 4836

Stoffel M et al. (2015) Estimates of volcanic-induced cooling in the Northern Hemisphere over the past 1,500 years. Nat Geosci 8:784-788. doi:10.1038/ngeo2526

Tierney JE, Tingley MP (2014) A Bayesian, spatially-varying calibration model for the TEX86 proxy. Geochim Cosmochim Acta 127:83-106. doi:10.1016/j.gca.2013.11.026

Tingley MP, Huybers P (2010) A Bayesian algorithm for reconstructing climate anomalies in space and time. Part I: development and applications to paleoclimate reconstruction problems. J Clim 23:2759-2781. doi:10.1175/2009JCLI3015.1

Tingley MP, Stine AR, Huybers P (2014) Temperature reconstructions from tree-ring densities overestimate volcanic cooling. Geophys Res Lett 41:7838-7845. doi:10.1002/2014g1061268

Tolwinski-Ward SE, Anchukaitis KJ, Evans MN (2013) Bayesian parameter estimation and interpretation for an intermediate model of tree-ring width. Clim Past 9:1481-1493. doi:10.5194/ cp-9-1481-2013

Tolwinski-Ward SE, Tingley MP, Evans MN, Hughes MK, Nychka DW (2015) Probabilistic reconstructions of local temperature and soil moisture from tree-ring data with potentially timevarying climatic response. Clim Dyn 44:791-806. doi:10.1007/ s00382-014-2139-z

van Albada SJ, Robinson PA (2007) Transformation of arbitrary distributions to the normal distribution with application to EEG test-retest reliability. J Neurosci Meth 161:205-211. doi:10.1016/j.jneumeth.2006.11.004

Viau AE, Ladd M, Gajewski K (2012) The climate of North America during the past 2000 years reconstructed from pollen data. Global Planet Change 84-85:75-83. doi:10.1016/j. gloplacha.2011.09.010

Wilson R et al. (2016) Last millennium northern hemisphere summer temperatures from tree rings: part I: the long term context. Quat Sci Rev 134:1-18. doi:10.1016/j.quascirev.2015.12.005

Young GHF, McCarroll D, Loader NJ, Kirchhefer AJ (2010) A 500-year record of summer near-ground solar radiation from tree-ring stable carbon isotopes. Holocene 20:315-324. doi:10.1177/0959683609351902

Zanchettin D et al. (2012) Bi-decadal variability excited in the coupled ocean-atmosphere system by strong tropical volcanic eruptions. Clim Dyn 39:419-444. doi:10.1007/s00382-011-1167-1

Zhang $\mathrm{H}$ et al. (2015) Modified climate with long term memory in tree ring proxies. Environ Res Lett 10:084020. doi:10.1088/1748-9326/10/8/084020

Zhong Y, Miller GH, Otto-Bliesner BL, Holland MM, Bailey DA, Schneider DP, Geirsdottir A (2011) Centennial-scale climate change from decadally-paced explosive volcanism: a coupled sea ice-ocean mechanism. Clim Dyn 37:2373-2387. doi:10.1007/ s00382-010-0967-z 